\title{
Preparation and Evaluation of Multi-Layer Anodes of Solid Oxide Fuel Cell
}

Diana Santiago ${ }^{1}$, John A. Setlock ${ }^{2}$ and Serene C. Farmer ${ }^{1}$

NASA Glenn Research Center, 21000 Brookpark Rd, Cleveland, OH 44135

University of Toledo, 2801 Bancroft, Toledo, $\mathrm{OH} 43606$

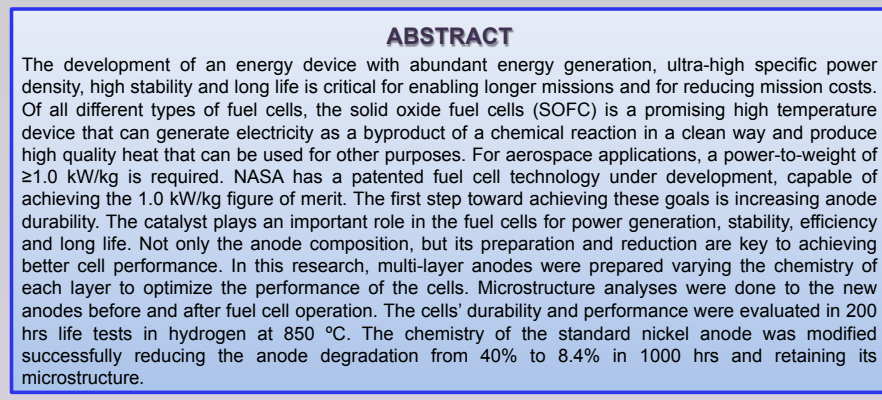

SOFC: MULTIPLE APPLICATIONS WITH SINGLE TECHNOLOGY

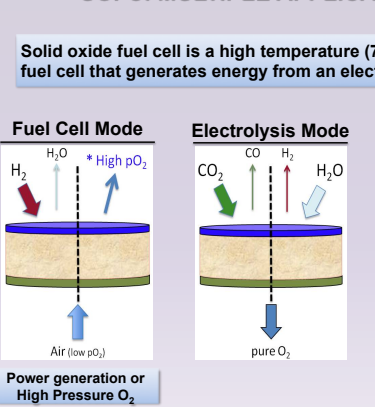

Long Endurance Flight

Solar panels provide power to
the Stack to electrolyze water
during the day and storer

Bi-Electrode-Supported Cells

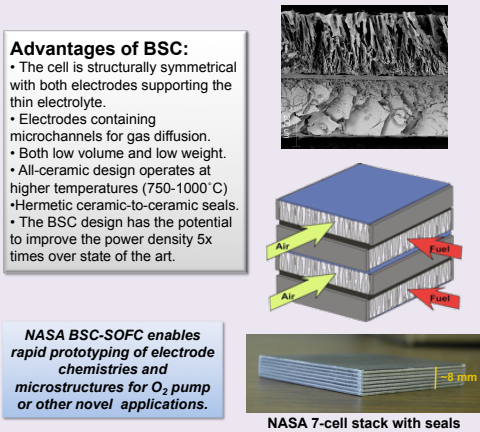

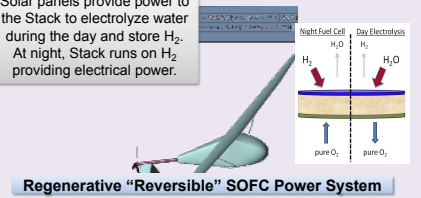
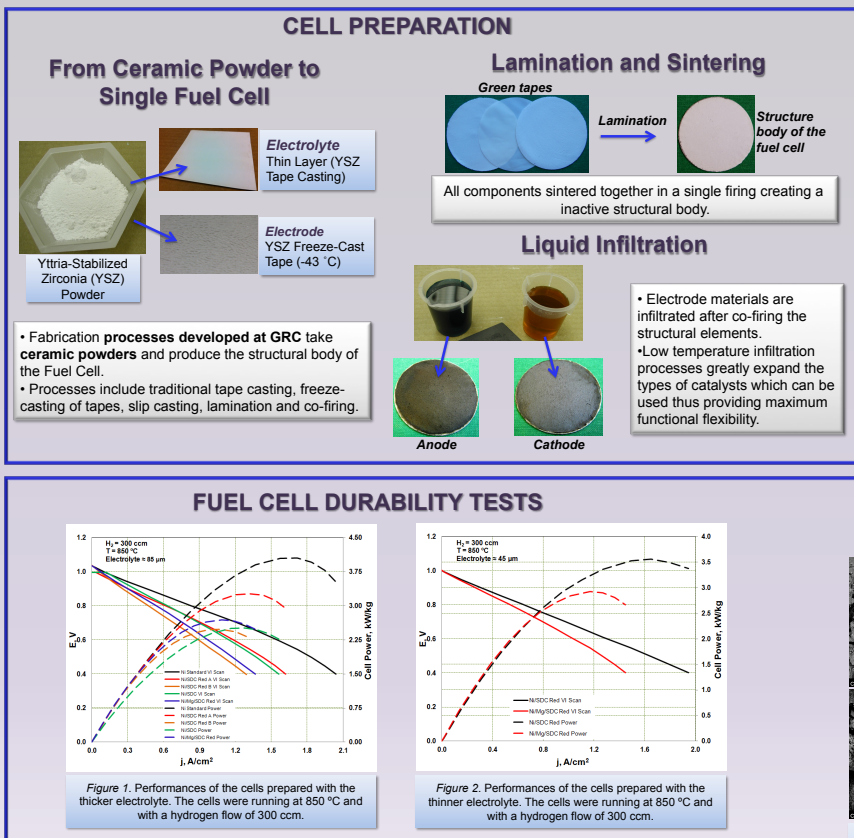
Power Generation Using
Methane Generated b b yn-
Situ Resource Utilization

SOFC Advantages:
- High efficiency

: High efficicncy
: High energy density
- loxible tuel capaphility

- Operating on oboth hydrogen
and hydrocarbon-based fuels

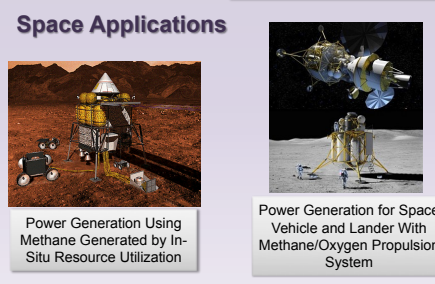

Fuel Cell Auxiliary Power Unit

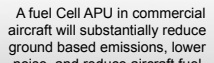

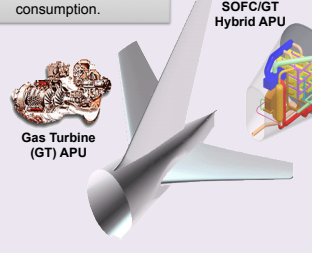

Ceramic Interconnects Removal of Metal Interconnect

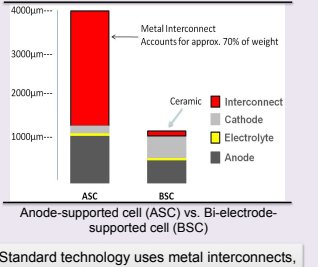

Standard technology uses metal interconnects,
accounting for $70 \%$ or the weingt, hich
reduces specific power density to $0.3 \mathrm{~kW} / \mathrm{kg}$.
Doise, and reduce aircraft fuel
consumption.

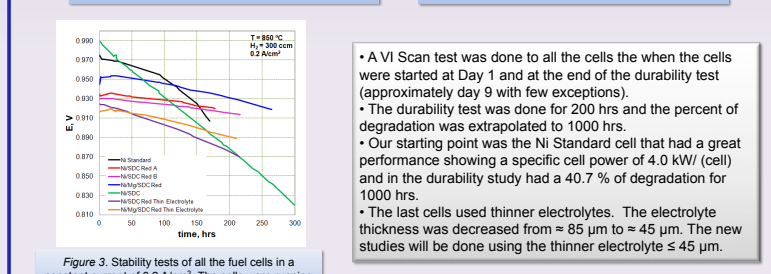

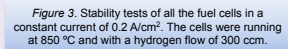
thickness was decreased from $\approx 85$ m to $\approx 45$ mm. The new
studies will be done using the thinner electrolyte $\leq 45$ m.

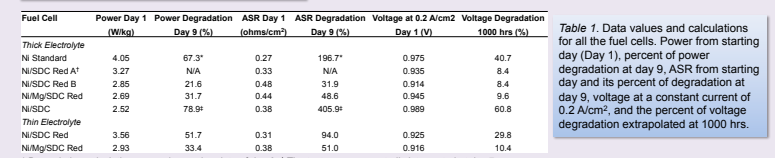

CONCLUSIONS

- The performance and stability tests and the SEM analysis confirms the importance of not only the electrode material but also
the electrode preparation process on the performance and especially the long term stability of the fuel cells. the electrode preparation process on the performance and especially the long term stability of the fuel cells.

- The fuel cells NiSDC Red have better stability than he fuel cells of Ni Standard, showing a decrease in the percent of 作 - Adding magnesium to the anode electrode helped to retain the microstructure after the cell performance and decreased the
. amount of nickel exaggerated growth on the top of the electrode. The performance was comparable to the N/SDC Red
with a $9.6 \%$ of degradation per $1000 \mathrm{hrs}$.
- Ssing a thin er elo - Using a thinner electrolyte provides

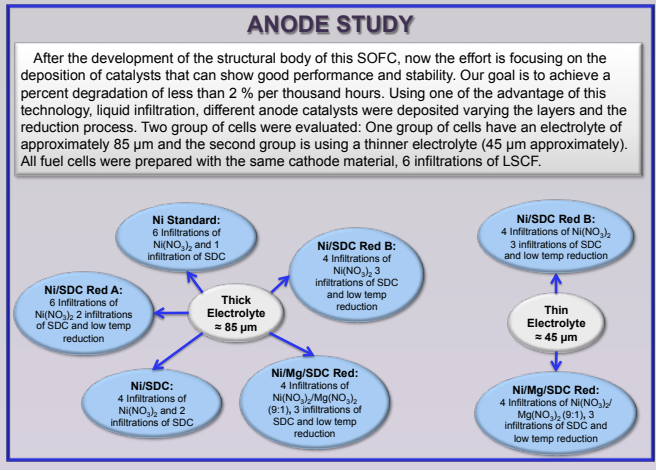

SEM ANALYSIS
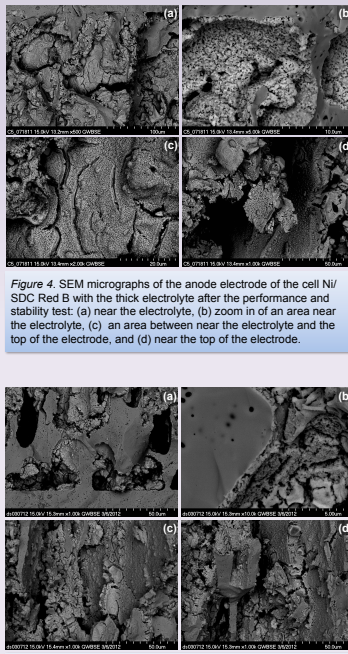

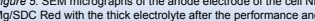

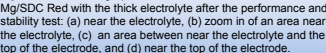

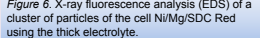

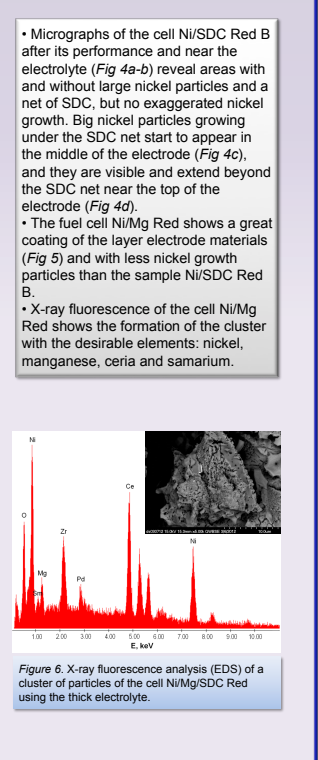

CURRENT AND FUTURE WORK - Ni anodes reduced at higher temperatures, currently being tested - New anodes will be created alternating the layers of nickel, magnesium and SDC and increasing the reduction temperature.
Better performance and stability is expected with these electrodes. - 2 ter performance and stability is expected with these electrodes.
- Different proportions between nickel and magnesium will be studied for the optimization. The reduction temperature also will be

increased for the cells.
The study of other compositions also is expected. 